\title{
A NATUREZA JURÍDICA DAS STOCK OPTIONS NO DIREITO DO TRABALHO BRASILEIRO
}

\author{
Daniel Queiroz Pereira ${ }^{1}$ \\ Lorena Miranda Pereira \\ dos Santos ${ }^{2}$
}

\section{Resumo}

O presente artigo tem por escopo analisar o Stock Option Plan, que consiste no sistema através do qual se busca incentivar o empregado e, consequentemente, aumentar a produtividade de uma sociedade anônima empregadora, através da concessão da opção de compra de ações, em condições geralmente mais vantajosas do que as encontradas no mercado bursátil. Em razão da inexistência de legislação específica no âmbito trabalhista e previdenciário há uma discussão travada entre os doutrinadores trabalhistas e os órgãos que compõem a estrutura da Justiça do Trabalho acerca da natureza jurídica que deve ser atribuída às Stock Options e, por conseguinte, os efeitos gerados na relação de emprego. Exercida a opção, poderá o beneficiário, após um período de carência, vender suas quotas, oportunamente no período em que as ações tiveram seus preços majorados. É a partir do eventual lucro obtido pelo empregado na venda das ações que surge a indagação acerca da natureza jurídica das Stock Options, questionando-se se devem receber o tratamento de salário ou de mero contrato mercantil.

Palavras-chave: Stock option. Natureza salarial. Mercado bursátil.

\section{INTRODUÇÃO}

\footnotetext{
${ }^{1}$ Professor Adjunto da Universidade Federal do Estado do Rio de Janeiro - UNIRIO. Diretor da Escola de Ciências Jurídicas da Universidade Federal do Estado do Rio de Janeiro - UNIRIO. Doutor em Direito da Cidade pela Universidade do Estado do Rio de Janeiro - UERJ. E-mail: danielqueiroz_uerj@infolink.com.br

${ }^{2}$ Bacharel em Direito pela Universidade Federal do Estado do Rio de Janeiro - UNIRIO. E-mail: lorena.direitoo8@yahoo.com.br
} 
O presente artigo constitui uma reflexão acerca da problemática da natureza jurídica das Stock Options (opção de compra de ações), quando analisadas no âmbito do Direito do Trabalho Brasileiro.

Muito embora tenham sido introduzidas no Brasil pela Lei das Sociedades por Ações, em 1976, até hoje não receberam qualquer regulamentação específica nas legislações trabalhista e previdenciária.

Nessa perspectiva, ante a ausência no ordenamento jurídico pátrio dos referidos dispositivos legais, a natureza jurídica das Stock Options, isto é, se possuem natureza salarial ou indenizatória, ainda é uma questão controvertida, ficando à margem das discussões doutrinárias e jurisprudenciais.

Trata-se, então, de assunto de extrema relevância, que não está limitado a uma mera conceituação, pois, a depender da natureza que lhes for atribuída - salarial ou indenizatória - as Stock Options repercutirão diretamente no contrato de trabalho, tanto na sua vigência, quanto na sua rescisão.

Isso porque, caso as Stock Options sejam consideradas como retribuição pela prestação de serviços prestados pelo empregado, deverão integrar a folha de pagamento e sobre elas incidirão os encargos trabalhistas e previdenciários previstos legalmente, representando reflexos diretos no que diz respeito a custos para o empregador.

Por outro lado, se lhes for atribuída natureza indenizatória, não incidirão nas verbas trabalhistas reflexas, nem servirão de base para o cálculo das contribuições previdenciárias.

Portanto, a abordagem que será realizada não tem a preocupação de abarcar as relações de trabalho lato sensu, se restringindo tão somente às relações de emprego que, nos termos do artigo $3^{\text {}}$ da Consolidação das Leis do Trabalho, são caracterizadas pela pessoalidade, habitualidade, subordinação e onerosidade.

Nesse contexto, o principal objetivo deste trabalho reside em analisar a verdadeira natureza jurídica das Stock Options, pautando-se nas controvérsias doutrinárias e dos tribunais trabalhistas sobre o tema para, então, se concluir se estarão sujeitas aos encargos trabalhistas e previdenciários.

ASPECTOS GERAIS DAS STOCK OPTIONS 


\section{Breve histórico}

O fenômeno das Stock Options teve sua origem nos Estados Unidos, na década de 50, ganhando destaque a partir dos anos 80.

Sua primeira centelha veio de Washington, quando a taxa do Imposto de Renda chegou ao patamar de $91 \%$ e, por essa razão, o Congresso decidiu que o lucro proveniente de ações fosse tributado com a taxa da mais valia e, posteriormente, com a taxa de $25 \%$, desde que se possuísse as ações por pelo menos um ano, o que acabou se tornando para alguns uma oportunidade fiscal atraente.

Nesse sentido, as Stock Options passaram a ganhar entre os norte-americanos, nas décadas de 1960 e 1970, o status de "paraíso fiscal". Todavia, em 1976, com a taxa do Imposto de Renda ainda elevada, na casa dos 70\%, os legisladores aboliram o benefício fiscal, e o lucro obtido a partir das ações passou a ser tributado de forma tão elevada como a renda regular.

Sua segunda centelha ocorreu com o plano adotado no governo de Ronald Reagan, na década de 1980, que baixou a taxa do Imposto de Renda inicialmente para 50\%, em 1981, e, posteriormente, em 1986, para 28\%. Essa política coincidiu com uma exagerada elevação no valor das ações da companhia norte-americana Dow Jones Industrial que passou de $\$ 800$ em 1982 para $\$ 11,500$ no ano de 2000 , sendo muito recompensador para aqueles que mantiveram suas ações.

Essa política teve uma influência ao redor do mundo e, como consequência, nesse período a adoção do Stock Option Plan começou a ser notado em empresas multinacionais que atuavam no Brasil. Na Europa, por sua vez, os efeitos das Stock Options passaram a ser notados a partir da década de 70, alcançando a sua plenitude nos anos 90.

Frise-se que, a princípio, as Stock Options eram um benefício concedido apenas aos altos executivos das companhias. Entretanto, com corte dos impostos e o aumento das ações, percebeu-se que a opção de ações era uma grande motivadora de funcionários e, sendo assim, passou a ser concedida aos empregados que não faziam parte do alto escalão. Trata-se, porém, de uma prática mínima, eis que a grande maioria 
dos beneficiados ainda são os grandes executivos; aqueles que exercem cargos de confiança.

\section{Conceito}

A fim de ser ter uma melhor conceituação do instituto das Stock Options, verifica-se, desde logo, imprescindível a transcrição dos dizeres de alguns doutrinadores.

Fábio Ulhoa Coelho conceitua as Stock Options da seguinte forma:

Trata-se de negócio jurídico, pelo qual a companhia se obriga, a partir da declaração de vontade do executivo beneficiário (exercício da opção) e pagamento por este do preço, a entregar-lhe ações de sua emissão, em quantidade e espécie previamente definidas no instrumento de opção. ${ }^{3}$

Maurício Godinho Delgado, ao seu turno, busca explicar as Stock Options como um mecanismo através do qual

A sociedade anônima empregadora estabelece a possibilidade de seus administradores ou empregados adquirirem ações da respectiva companhia, cotadas em bolsas de valores, em condições relativamente mais vantajosas do que a simples aquisição diversa e à vista no mercado bursátil. Exercendo a opção, o trabalhador se torna proprietário de certo lote de ações, podendo vendê-lo oportunamente no mercado acionário observada, na época, a cotação encontrada no pregão. ${ }^{4}$

Já Icíar Alzaga Ruiz, em sua obra específica sobre o tema, intitulada de "Las Stock Options - Un estúdio del punto de vista del derecho del trabajo y de la seguridad social" define o instituto da seguinte forma:

As Stock Options são contratos que conferem ao seu titular, gratuitamente ou por um preço determinado, o direito de adquirir ou subscrever um determinado número de ações da concessora ou de uma das empresas do mesmo grupo econômico,

\footnotetext{
${ }^{3}$ COELHO, Fábio Ulhoa. Curso de Direito Comercial: Direito de Empresa. 16 ed. São Paulo: Saraiva, 2012, p.197.

${ }^{4}$ DELGADO, Maurício Godinho. Curso de Direito do Trabalho. 11 ed. São Paulo: LTr, 2012. p.725 vol.08, $n^{\circ}$. 01, Rio de Janeiro, 2015. pp. 21-50 24
} 
durante um prazo determinado (opção americana) ou em uma data concreta (opção europeia) e, eventualmente, sempre que se cumpram certas condições adicionais ${ }^{5}$

Da mesma forma, preleciona Alice Monteiro de Barros que o regime das stock options se caracteriza por permitir que os empregados comprem ações da empresa em um determinado período e por preço ajustado previamente. Se o valor da ação ultrapassa o preço, o beneficiário obtém lucro, e, a partir daí, duas alternativas lhe são oferecidas: revender de imediato a mais valia ou guardar os seus títulos e se tornar um empregado acionista.

Ainda no mesmo sentido, Vólia Bomfim Cassar afirma que, por vezes, alguns empregadores oferecem aos seus empregados o direito de adquirir ações da companhia por um custo abaixo do mercado (stock option). Uma vez adquiridas voluntariamente pelo trabalhador, será possível a venda quando da valorização do seu valor econômico. Salienta, entretanto, que esse exercício de opção de compra de ações da empresa empregadora envolve riscos, pois o empregado poderá ganhar ou perder com a operação ${ }^{6}$.

A partir da reflexão dos ensinamentos dos autores mencionados acima, pode-se concluir que Stock Option Plan, ou Plano de Opção Compra de Ações na língua vernácula, é, como o próprio nome já diz, um plano através do qual se concede a um empregado de uma sociedade anônima a opção de adquirir, comprar as ações da mesma, ou de alguma outra empresa pertencente ao mesmo grupo econômico ${ }^{7}$.

Através desse sistema, o empregado contemplado, após um período ou data predeterminados, terá o direito de adquirir ações de sua empregadora por um valor já fixado, ou por aquele da época em que o benefício foi concedido que, geralmente, apresenta condições mais vantajosas do que a compra realizada diretamente no mercado de ações.

\section{Fases e características do Stock Option Plan}

\footnotetext{
${ }^{5}$ RUIZ, Acíar Alzaga. Las Stock Options - Un estúdio del punto de vista del derecho del trabajo y de la seguridad social. Madrid: Civitas Ediciones, 2003. p. 43

${ }^{6}$ CASSAR, Vólia Bomfim. Direito do Trabalho. 4 ed. Rio de Janeiro: Impetus, 2010. p.884

${ }^{7}$ MARTINS, Sergio Pinto. Direito do Trabalho. 26 ed. São Paulo: Atlas S.A., 2010. p. 244 vol.08, no. 01, Rio de Janeiro, 2015. pp. 21-50 
Ao se explorar o tema das Stock Options, é também essencial a análise de suas fases para a melhor compreensão deste instituto. Por serem assuntos que se tocam, será feito, convenientemente, um exame de suas principais características, que, deve-se dizer, estão presentes independente do país nas quais são adotadas. Esses atributos nada mais são do que, na verdade, os termos e condições que regularão o exercício da Opção de Compra das Ações.

A primeira fase é a concessão da opção, que deverá ser formalizada através de um Plano de Concessão de Ações, devidamente aprovado pela Assembleia Geral da companhia. Esse benefício poderá depender unicamente da vontade do empregador ou de alguma condição do trabalho, como o cumprimento de uma meta, pessoal ou coletiva, por exemplo.

Neste ponto, importa frisar que a Comissão de Valores Mobiliários - CVM, através de sua Deliberação no 3.712 de 13.12.2000, estabeleceu que deve haver obrigatoriamente a divulgação de nota explicativa do Plano de Opção de Compra de Ações.

Muito embora tenha recebido esse privilégio, o empregado não poderá exercer desde logo a opção. Deverá ele observar um prazo, conhecido como "Carência" ou, no inglês, "Vesting", que é o intervalo de tempo entre o momento em que a opção é concedida e o momento em que o empregado poderá de fato exercer o seu direito de compra.

A depender do objetivo que a companhia pretende alcançar, a carência pode variar, mas, usualmente, esse lapso temporal é de longo prazo.

A partir daí, convém ressaltar que a opção de comprar as ações nada mais é do que, a princípio, uma mera expectativa de direito subjetivo. O beneficiado deverá se manter nos quadros de empregados de sua empregadora até que possa exercer de fato a opção de compra das ações. Ou seja, não se trata de um direito automático.

Em outras palavras, decorrido o período de carência, caso o empregado tenha permanecido na empresa, esse direito terá se incorporado ao patrimônio jurídico de seu titular e, sendo assim, poderá adquirir as ações. Por outro lado, caso tenha saído da empresa, seja por qualquer motivo, antes de passado o referido prazo, não fará jus a exercer a opção, uma vez que esse direito se encerra imediatamente com o término do contrato de trabalho. 
A respeito desta questão, sustenta Sério Pinto Martins:

O empregado tem direito a um lote de ações. Se ele continuar na empresa por um certo período, ganha o direito de comprar as ações pelo preço do dia da reserva e vendê-la pelo valor atualizado.

É uma participação na valorização futura das ações da empresa. O prazo costuma ser de três, cinco ou dez anos. Caso o empregado deixe a empresa antes disso, perderá o seu direito. ${ }^{8}$

A carência pode não apenas representar um intervalo de tempo, mas também uma data específica predeterminada, é a chamada Carência com Data Pré-Fixada (Cliff Vesting).

Da mesma forma, há a possibilidade de uma certa percentagem de opções serem executadas a cada ano. São as chamadas Carência Direta (Straight Vesting) ou Carência em Passos (Step Vesting). Através da primeira, a cada ano poderá ser adquirido um percentual igual de ações, ao passo que, pela segunda, esse percentual varia a cada ano.

A título de ilustração, cita-se o seguinte exemplo: se um empregado for beneficiado com a opção de adquirir 1.000 (mil) ações, com 5 (cinco) anos de Carência Direta, isso significa dizer que a cada ano poderá exercer 200 (duzentas) opções, o que representa 20\% (vinte por cento) ao ano. Contudo, se fosse o caso de Carência em Passos, o percentual variaria a cada ano, podendo, inclusive, oscilar de acordo com, por exemplo, o nível de classificação do empregado dentro da empresa.

A carência poderá, ainda, estar associada ao desempenho da companhia, de modo que o empregado privilegiado só poderá exercer sua opção após atingido um determinado objetivo.

Cumprido o período de carência, e, caso necessária, cumprida a condição preestabelecida, passa-se para a segunda fase do Stock Option Plan, qual seja, a possibilidade do exercício da opção de compra das ações. Nesta etapa, deixou-se de ter uma mera expectativa de direito, passando-se a ter um direito adquirido. Aqui o exercício da opção só dependerá da vontade do empregado.

\footnotetext{
${ }^{8}$ MARTINS, Sergio Pinto. Direito do Trabalho. 26 ed. São Paulo: Atlas S.A., 2010. p. 244
} vol.08, nº. 01, Rio de Janeiro, 2015. pp. 21-50 
Conforme já mencionado, ao empregado é oferecido um lote de ações, por um valor predeterminado ou, mais usualmente, pelo valor da época em que o benefício lhe foi concedido (Grant Price ou Exercise Price).

Neste segundo estágio, caberá ao empregado avaliar um outro atributo das Stock Options, qual seja, o seu "Valor", de modo a verificar se houve aumento ou queda no preço das ações, ou seja, se o valor das ações no mercado acionário está maior ou menor, se comparado ao seu valor da emissão. Obviamente, irá optar em comprá-las, caso tenha havido um acréscimo em seus preços, a fim de que possa obter lucro com o negócio.

Caso opte por adquirir as ações, tem início a terceira fase, que é a da compra das ações. Esta é a etapa em que haverá o exercício do direito de opção.

Aqui, deverá o empregado se atentar para a chamada Validade ou Expiration, que representa o prazo de vencimento para que o empregado possa exercer a opção, a partir do dia em que esse benefício lhe foi concedido. Tenha-se presente, que este prazo poderá ser determinado tanto para o exercício da compra, como da venda das ações.

Tendo optado pela compra das ações, o empregado que se tornou acionista, terá posteriormente a opção de vender as ações, se lhe for e quando for mais conveniente. Instaura-se, a partir daí, a quarta e última fase do Stock Option Plan.

Deve-se ter em mente que no Plano de Opção de Ações não é conferido ao empregado a obrigação de adquirir as ações, mas sim uma faculdade, podendo ele optar pela compra das ações, ou não. Tudo vai depender de seu interesse no momento.

Além de representar uma faculdade, como devidamente esclarecido acima, as Stock Options também possuem como uma de suas características a volatilidade, que significa o risco que o empregado assume de não auferir lucros com a compra e venda das ações. Este atributo será melhor analisado mais à frente.

\section{OBJETIVOS DAS STOCK OPTIONS}

O instituto das Stock Options reflete positivamente tanto para os empregadores, quanto para os empregados. Para os primeiros, revela-se como uma ferramenta eficaz de alinhamento de interesses entre empregados e acionistas; de captação e retenção de 
empregados chaves; e de crescimento das finanças. Para os segundos, mostra-se como uma forma de obtenção de lucros ilimitados, que não são acompanhados pelos ajustes na renda fixa.

Conforme já devidamente desenvolvido, o intervalo exigido entre a data em que é feita a oferta do Plano de Opção de Ações e o momento a partir do qual o empregado já poderá exercer a sua opção - denominado de tempo de carência ou vestin - está associado a um dos objetivos originais dos empregadores ao adotarem o Stock Option Plan, qual seja, o de reter a longo prazo a mão de obra fundamental para a companhia.

O empregado favorecido e interessado em obter as ações, deverá permanecer trabalhando na empresa por, normalmente, três, cinco, ou dez anos, até ter o efetivo direito de exercer a sua opção, momento a partir do qual passará a ser acionista da empresa para o qual trabalha, o que também é uma garantia da preservação dessa mão de obra, até que ele se decida pela venda das ações adquiridas.

Além de garantir a permanência de empregados importantes à companhia, o Stock Option Plan também possibilita a captação de outros talentos, que se sentem atraídos com as possibilidades desse plano.

Outra razão é a de manter seus empregados incentivados. Ao ostentarem a condição de acionistas, passam a ter interesse na distribuição dos lucros, uma vez que começam a receber uma fração dos recursos atrelados aos resultados da companhia. Por essa razão, sentem-se estimulados, e trabalham visando aumentar a produtividade e rentabilidade da empresa.

Para os empregados, optar por adquirir as ações representam não apenas receberem o status de acionistas, mas também de obter ganhos ilimitados, uma vez que, ao contrário da renda fixa, as ações não possuem limites de lucros.

Visando alcançar esse objetivo, o empregado abre mão de parte de seu rendimento fixo para obter as ações. Contudo, na posse das mesmas, tem a possibilidade de lucrar com a elevação das ações, podendo facilmente superar qualquer forma realista de remuneração fixa.

Deve-se ressaltar, entretanto, que as razões que levam os empregadores a adotarem o Stock Option Plan, e aos empregados a optarem por adquirirem as ações, não se limitam àquelas descritas acima, sendo, tão somente, a exposição dos principais motivos e dos fins que se pretende alcançar. 


\section{REGULAMENTAÇÃO E REQUISITOS LEGAIS}

As Stock Options foram introduzidas no ordenamento jurídico brasileiro em 1976, através da Lei no. 6.404, conhecida como Lei das Sociedades por Ações. Assim está previsto no parágrafo $3^{\circ}$ de seu artigo 168 :

Art. 168. O estatuto pode conter autorização para aumento do capital social independentemente de reforma estatutária.

[...]

$\S 3^{\text {o }} \mathrm{O}$ estatuto pode prever que a companhia, dentro do limite de capital autorizado, e de acordo com plano aprovado pela assembléia-geral, outorgue opção de compra de ações a seus administradores ou empregados, ou a pessoas naturais que prestem serviços à companhia ou a sociedade sob seu controle.

É de se verificar que, ainda que as companhias cada vez mais recorram às Stock Options, fazendo crescer a sua importância, no Brasil sua regulamentação limita-se ao dispositivo supratranscrito, isto é, carece de legislação específica nas esferas trabalhista, previdenciária e até mesmo tributária.

Cumpre preliminarmente observar que as Stock Options só podem ser implementadas em sociedades anônimas, isto é, aquelas cujo capital social esteja dividido em ações.

Do que se percebe do referido diploma, os requisitos necessários para a adoção do Plano de Opção de Ações são os seguintes: (i) previsão expressa no estatuto social; (ii) existência de capital autorizado; (iii) prévia aprovação de um Plano de Concessão pela Assembléia Geral.

O limite do aumento do capital social poderá ser estabelecido com base no valor do capital ou em número de ações, lembrando sempre que esse aumento deverá estar previsto no estatuto social da companhia, que deverá indicar as hipóteses em que as ações poderão ser emitidas, sempre dentro do limite autorizado.

Essas condições previstas legalmente têm por objetivo proteger os acionistas, garantindo-lhes moderação nas solicitações de novos capitais, a fim de que suas 
posições acionárias não sejam ameaçadas quando da impossibilidade de atender a todos os aumentos arbitrariamente deliberados.

Insta observar, entretanto, que o parágrafo $3^{-0}$ do artigo 171 desta mesma lei é claro ao estabelecer que, desde que cumpridas as condições acima, os acionários não terão direito de preferência:

Art. 171. Na proporção do número de ações que possuírem, os acionistas terão preferência para a subscrição do aumento de capital.

[...]

$\S 3^{0}$ Os acionistas terão direito de preferência para subscrição das emissões de debêntures conversíveis em ações, bônus de subscrição e partes beneficiárias conversíveis em ações emitidas para alienação onerosa; mas na conversão desses títulos em ações, ou na outorga e no exercício de opção de compra de ações, não haverá direito de preferência.

Isso significa dizer que, dentro do limite do capital autorizado, nenhum acionista terá prioridade de subscrever ações, com o fim de manter intacta a sua posição na participação do capital social da companhia.

\section{A NATUREZA JURÍdicA DAS STOCK OPTIONS NO DIREITO PÁTRIO}

Abordados os aspectos gerais concernentes às Stock Options, adentra-se às discussões a respeito de sua natureza jurídica.

Percebe-se, desde logo, que o legislador brasileiro não se pronunciou acerca das Stock Options especificamente no escopo trabalhista, previdenciário e até mesmo tributário. Sendo assim, toda matéria está aberta à interpretação, estando limitada à exposição dos entendimentos dos doutrinadores e julgadores e, como consequência disto, a resolução de casos concretos envolvendo o Stock Option Plan fica a critério da percepção de cada juízo.

Maurício Godinho Delgado apresenta a discussão sobre a natureza jurídica das Stock Options, trazendo à baila os argumentos favoráveis e desfavoráveis para a caracterização da natureza salarial deste instituto: 
Qual a natureza jurídica das stock options? Enquadram-se como parcela de natureza salarial (com as consequências advindas do efeito expansionista circular dos salários) ou, ao reverso, não tem semelhante natureza?

As ponderações em favor do enquadramento como vantagem salarial indicam a circunstância de elas constituírem inegável acréscimo econômico conferido pelo empregador ao empregado em virtude da existência do contrato de trabalho, tendo, assim, caráter retribuído (art. 457, caput e $\S$ 1o e art. 458, caput, ambos da CLT). Entregues, ilustrativamente uma vez ao ano, seriam enquadradas na parcela gratificação, com os efeitos da Súmula 253 do TST.

Em favor do enquadramento não salarial despontam argumentos que insistem que a parcela tem iniludível caráter de participação nos lucros ou resultados da empresa, sem natureza salarial por força de direto comando constitucional (art. $7^{\mathbf{o}} \mathrm{XI}$, ab initio, $\mathrm{CF} / 88)$. As stock options distanciam-se também dos salários em face de posicionarem o titular das ações em locus nitidamente empresarial, inclusive assumindo riscos típicos da empresa, mesmo que limitados ao montante de seu estoque acionário. A argumentação se completa no sentido de ser a parcela essencialmente volátil - característica inerente às ações -, o que mais ainda a separa dos caracteres próprios dos salários.

Do ponto de vista prático, há ainda outro aspecto que pode influenciar no enquadramento jurídico da verba: a absoluta ocasionalidade (ou não) de sua oferta. Se as stock options forem ofertadas de maneira manifestamente ocasional, sem repetição no contrato (ou com repetição muito longínqua - bianual, trianual ou similar), não atenderão à ideia de habitualidade, que seria imprescindível para seu enquadramento nas gratificações.

Ao revés, sendo repetidas em lapsos temporais relativamente curtos, poderão, sim, considerando estritamente esse ponto de vista, ser assimiladas às parcelas gratificatórias 9 .

Sobre este tema, Sérgio Pinto Martins conclui que a stock option não pode ter natureza salarial, pois o empregado paga para exercer o direito de opção. Não se

\footnotetext{
${ }^{9}$ DELGADO, Maurício Godinho. Curso de Direito do Trabalho. 11 ed. São Paulo: LTr, 2012. p. 725 e 726. 
constituindo em algo que lhe é dado de graça pelo empregador, que representa um plus. Deste modo, nas palavras do autor

A natureza jurídica da opção de compra de ações é mercantil, embora feita durante o contrato de trabalho, pois representa mera compra e venda de ações. Compreende a opção um ganho financeiro, sendo até um investimento feito pelo empregado nas ações da empresa. Por se tratar de risco do negócio, em que as ações ora estão valorizadas, ora perdem seu valor o empregado pode ter prejuízo com a operação. É uma situação aleatória, que nada tem a ver com o empregador em si, mas com o mercado de ações ${ }^{10}$.

Vólia Bomfim Cassar corrobora tal posicionamento, uma vez que entende que o "ganho" eventualmente obtido pelo trabalhador com a venda das ações de sua empregadora não tem natureza salarial, pois é espécie de operação financeira no mercado de ações. Ademais, é pago em razão do negócio, e não da prestação de serviço. Neste ponto, ressalta ainda que o empregado corre todos os riscos da ação cair e, por isso, sofrer prejuízo com a prática ${ }^{11}$.

Do que se percebe, é que um dos argumentos mais consistente utilizado por aqueles que defendem a natureza não salarial das Stock Options é o risco assumido pelo empregado.

O artigo $2^{\underline{0}}$ da CLT dispõe que ao empregador cabem os riscos do negócio, não podendo esses serem transferidos ao empregado: "Considera-se empregador a empresa, individual ou coletiva, que, assumindo os riscos da atividade econômica, admite, assalaria e dirige a prestação pessoal de serviço”.

Se por um lado o empregado deixa de limitar sua renda a uma remuneração fixa, por outro, assume o risco durante o período de crise do mercado financeiro. Ao invés de receber renda fixa nos períodos de crise do mercado de ações, os detentores das Stock Options veem seus rendimentos se dissiparem, ao mesmo tempo que o mercado se contrai.

As Stock Options têm permitido aos empregadores transferirem uma porção do risco de compensação de trabalho aos empregados. Contudo, importante ressaltar que, para não serem consideradas como parcelas remuneratórias, o risco deve ser

\footnotetext{
${ }^{10}$ MARTINS, Sergio Pinto. Direito do Trabalho. 26 ed. São Paulo: Atlas S.A., 2010. p. 247 e 248. ${ }^{11}$ CASSAR, Vólia Bomfim. Direito do Trabalho. 6 ed. Rio de Janeiro: Impetus, 2012. p. 884. 
integralmente assumido pelo trabalhador, ou seja, todo o risco deve recair sobre o empregado.

Como se não bastasse, não se pode deixar de levar em consideração a inexperiência do trabalhador. Ao se explanar acerca do histórico do Stock Option Plan, relatou-se que este era concedido, a princípio, apenas aos altos executivos da companhia, aqueles que desempenhavam cargos de confiança. Com o tempo, passou-se a conceder esse benefício aos demais empregados, aqueles que não pertenciam ao topo da pirâmide do quadro de funcionários da empresa.

Nesse sentido, muitos detentores de opção de compra de ações não-executivos possuem o gravame da falta de experiência nessa atividade. Muitos não têm o tempo ou os recursos necessários para gerir de forma eficaz suas ações. Logo, a falta de conhecimento desses empregados muitas vezes fazem com que percam todos os seus investimentos no mercado acionário.

A volatilidade é, portanto, mais uma das características das Stock Options, visto que se trata de um negócio de risco. Assim sendo, se o valor das ações à época do exercício da opção for inferior ao valor de compra, preço de emissão, o empregador não auferirá qualquer vantagem, muito pelo contrário. Tampouco, receberá qualquer indenização por parte do empregador.

Repita-se que, ainda que o risco seja uma das principais características para que não seja atribuída natureza salarial ao Stock Options Plan, necessário se faz que o obreiro assuma a sua totalidade. Logo, se por qualquer motivo for possível se ter uma estimativa dos rendimentos que serão obtidos pelo empregado através do Plano, deverá ser configurado o caráter remuneratório do lucro obtido.

Neste mesmo sentido, está o entendimento do Colendo Tribunal Regional do Trabalho da Sétima Região, manifestado através da seguinte ementa:

STOCK OPTION PLAN NATUREZA JURÍDICA.

Tais contratos têm natureza jurídica eminentemente mercantil, posto que onerosos, restando claro que os riscos assumidos na valorização ou não das ações 
correm por conta exclusiva dos empregados que a ele aderirem. Portanto, não devem ser considerados como parte da remuneração ${ }^{12}$.

À vista disso, se, após a concessão do benefício, o empregador alterar as regras do Plano Compra de Ações, com o intuito de favorecer o empregado e aumentar os seus ganhos, há a possibilidade de caracterização da natureza salarial, muito embora haja jurisprudência na Justiça do Trabalho no sentido da não caracterização.

Essa manipulação pode ocorrer, por exemplo, quando a companhia altera o valor de compra das ações pelo empregado, de acordo com as variações do mercado e após a concessão deste benefício. É o chamado Repricing. Assim, por exemplo, se as ações desvalorizam no mercado bursátil, o empregador diminui o preço de emissão para que o empregado adquira as ações e, dessa forma, ele consegue ajustar os lucros que serão obtidos, mantendo, assim, um controle sobre os riscos do Plano, que, neste caso, não estará recaindo todo sobre o trabalhador.

Em junho de 2013, o Conselho Administrativo de Recursos Fiscais (CARF) julgou dois processos administrativos - nos. 15889.000245/2010-46 e 10980.724030/2011-33 cuja principal questão de ambos era a tributação dos Planos de Stock Option, envolvendo as companhias América Latina Logística (ALL) e a COSAN.

Em sua defesa, a ALL alegou que a opção de compra de ações é concedida como incentivo a seus empregados, e não como uma forma de contraprestação e que se trata de uma questão de cunho cível, comercial. Argumentou, ainda, que os lucros auferidos através do Stock Option Plan não podem ser considerados como parcela remuneratória, uma vez que

1. O exercício da opção de compra é uma faculdade dos empregados beneficiados, ou seja, depende unicamente de sua escolha;

2. Representam uma onerosidade aos trabalhadores, vez que necessitam recorrer a seus recursos financeiros, a fim de se comprar as ações; e

3. O risco que este negócio representa, já que está sujeito às oscilações do mercado de ações. Por fim, afirmou que a CVM exige que as Stock Options sejam classificadas como remuneração apenas para fins contábeis.

\footnotetext{
${ }^{12}$ Processo no o183600-12.2012.5.07.0009 - RO, Relatora: Lais Maria Rossas Freire, Órgão Julgador: $7^{\mathrm{a}}$ Turma - Pelo do Tribunal, Julgamento: 05/08/2008, Data de Publicação: 11/09/2008 DOJTe. Disponível em: <http://www.jusbrasil.com.br/jurisprudencia/16911856/recurso-ordinario-ro1836001220025070009-ce-018360o-1220025070009-trt-7>. Acesso em: 29/o6/2013. 
Por outro lado, afirmou Raquel Godoy, Procuradora da Fazenda que atuou no feito, que havia natureza salarial, pois o benefício concedido aos empregados, qual seja, de compra das ações por um valor abaixo do mercado, era decorrente do contrato de trabalho. Isso porque foi concedido pelas companhias tão somente durante a vigência do pacto laboral. Ainda de acordo com a ela, o empregado não estava sujeito aos riscos do negócio, posto que, em 2008, quando houve uma grande queda no mercado bursátil, em decorrência da crise econômica, o plano de concessão da opção foi substituído por outro mais vantajoso.

Ocorreu que as companhias, deparando-se com a brusca queda do valor das ações no mercado, cancelou o antigo Plano de Concessão das Stock Options, e o substituiu por outro com valor de emissão menor. Essa medida foi adotada pela empregadora, a fim de manter no mesmo patamar os lucros que seriam obtidos pelos empregados contemplados antes e depois da crise econômica, o que evidencia que sobre o empregado não estavam recaindo quaisquer riscos.

A autora ainda acrescentou que no caso do Plano de Opção de Compra de Ações ofertado pela COSAN, o valor de emissão pago por cada ação pelo empregado era muito baixo - R\$ 6,oo (seis reais). Sendo assim, por ser muito discrepante se comparado ao valor de mercado, as chances de não obtenção de lucros são mínimas. Ademais, a empregadora ainda adotava a modalidade de Venda no Mesmo Dia (Same-day-sale). Por essa espécie de exercício da opção, o empregado após o exercício das opções, pode vendê-las imediatamente. Não há riscos neste plano, uma vez que basta que o empregado verifique se no dia da compra das ações o valor de mercado está mais elevado que o valor de emissão. Obviamente que se estiver abaixo, ele não irá exercer a opção.

Durante o julgamento, três votos foram proferidos em favor das contribuintes e outros três contrários. Por essa razão, a divergência foi resolvida por voto de qualidade, isto é, voto de desempate do presidente da Câmara, posição esta ocupada por um conselheiro indicado pela Fazenda Nacional. A questão foi decidida a favor da Receita Federal, sendo entendido que os ganhos obtidos com a compra e venda das ações pelos funcionários devem incidir nas contribuições previdenciárias. Além disso, concluiu-se também que não havia riscos, incertezas nesse negócio, características estas imprescindíveis para a não configuração do caráter remuneratório. 
O valor original do auto de infração da ALL é de cerca de 15 milhões de reais, ao passo que o da COSAN é de aproximadamente 30 milhões de reais. Até julho do ano corrente ainda não houve a publicação de tais decisões, das quais ainda há o cabimento de recurso.

Outro argumento contrário à natureza salarial é a onerosidade do Stock Option Plan. Afirma Sérgio Pinto Martins que "se o empregado paga pelo exercício da compra de ações, não se pode falar em natureza salarial, pois a prestação é onerosa para o trabalhador.". ${ }^{13}$

O Plano de Opção de Compra de Ações não pode ser confundido com a distribuição gratuita de ações. No primeiro é concedida a oportunidade de se comprar e vender as ações da empresa para o qual se trabalha ou outra pertencente ao mesmo grupo econômico. Na segunda, tem-se a concessão gratuita de ações, em geral, para os altos executivos, como uma forma de incentivá-los e aumentar o comprometimento com o empregador, já que se tornam acionistas, passando a fazer jus à distribuição dos resultados. Não há qualquer restrição, prazo de carência ou tampouco que se pagar por essas ações.

É defendida também a inexistência de habitualidade no Plano de Opção de Compra de Ações. Feita a proposta, o empregado beneficiado só poderá exercer sua opção após um período de carência que, geralmente, é de longo prazo, podendo variar em anos. Logo, não resta caracterizada a habitualidade do Plano.

Outra questão é a facultatividade no exercício da opção de compra das ações. Como já relatado, o empregado beneficiado não está obrigado a exercer a opção. Tratase de uma faculdade, ou seja, seu exercício é voluntário e depende unicamente da vontade e disponibilidade de recursos do obreiro.

Este atributo das Stock Options vai de encontro com uma das características mais essenciais do salário, qual seja, sua irrenunciabilidade. Não pode o trabalhador abrir mão da retribuição de seus serviços, posto que é um direito constitucional irrenunciável, mas pode deixar de exercer a opção de compra de ações, se assim desejar. Logo, não pode ser caracterizada como parcela remuneratória.

\footnotetext{
${ }^{13}$ MARTINS, Sergio Pinto. Direito do Trabalho. 26 ed. São Paulo: Atlas S.A., 2010. p. 248
} 
Outrossim, já restou abordado que um dos objetivos originais da Stock Options é a retenção de funcionários importantes para a companhia, o que contribui por não se entender pela sua natureza remuneratória. O empregado não é contemplado com a Opção de Compra de Ações como uma forma de retribuição pelos serviços prestados, mas sim para aumentar seu comprometimento e incentivá-lo a permanecer nos quadros de empregados da empresa.

O salário, de forma específica, e a remuneração, de forma mais ampla, são pagos ao empregado em decorrência de seu trabalho. Isso porque o contrato de trabalho é sinalagmático. No caso das Stock Options, elas não são pagas como uma contraprestação. É mais uma estratégia do empregador em manter empregados chaves.

Para Alice Monteiro de Barros, as Stock Options "não representam um complemento da remuneração, mas um meio de estimular o empregado a fazer coincidir seus interesses com o dos acionistas.”. E acrescenta: "no Brasil, o instituto também não possui feição salarial [...]”.

Ao defender pela natureza mercantil das Stock Options, Sérgio Pinto Martins segue a seguinte linha de raciocínio:

O direito de opção não se enquadra no $\S 1^{\mathbf{o}}$ do art. 457 da CLT, pois não representa comissão, percentagem gratificação ajustada, diárias para viagem e abonos pagos pelo empregador. Não se trata de gratificação porque o empregador não paga o valor, mas o obreiro paga para obter o direito de comprar as ações. Compreende fatores aleatórios à companhia, como a valorização das ações no mercado.

É prêmio? O prêmio é pago em virtude de um esforço do empregado. É um salário-condição. No caso, não há qualquer esforço do empregado. Este trabalha normalmente, não ganha algo a mais pela prestação de serviços. $\mathrm{O}$ empregado não tem de atingir a condição estabelecida pelo empregador para fazer jus à opção de compra de ações.

[...] Não se enquadra a stock option como espécie de salário-utilidade, pois não representa para o empregado um plus obtido com seu trabalho, mas decorre do desempenho das ações da companhia.

Não é espécie de participação nos lucros, pois a questão não decorre da existência de lucros, mas da valorização das ações do empregador.

$[\ldots]$ 
Se se entender que a prestação é uma espécie de salário variável, o empregador também teria de pagar ao empregado a diferença entre o valor da opção e o valor de venda, se este último fosse menos do que o primeiro, pois o trabalhador não pode assumir os riscos de sua atividade (art. $2^{-0}$ da CLT). Entretanto isso não ocorre.

Não se poderia dizer que é remuneração a opção de compra em que o empregado tem prejuízo no mercado financeiro. ${ }^{14}$

Demonstrados os argumentos utilizados por aqueles que julgam serem as Stock Options apenas um contrato de natureza mercantil, sem qualquer caráter remuneratório, parte-se adiante para as justificativas daqueles que entendem de modo diverso e que sustentam a natureza salarial do Plano de Opção de Compra de Ações.

Para Icíar Alzaga Ruiz, as Stock Options estão associadas ao caráter sinalagmático do contrato de trabalho, sendo concedidas como retribuição ao empregado, ou seja, como contraprestação pela prestação de seus serviços, correspondendo a uma parcela variável da remuneração deste e que irá integrar o seu salário.

Segundo a referida autora, tem-se caracterizada a natureza salarial das Stock Options, uma vez que também podem ser concedidas como uma forma de complementação do salário do trabalhador, que são decorrentes dos resultados positivos da companhia. Acrescenta que a possibilidade de as Stock Options serem concedidas por empresa diversa daquela para o qual trabalha o empregado não impossibilita que as mesmas façam parte de sua remuneração, mas desde que pertençam a um mesmo grupo econômico.

Ainda de acordo com o seus ensinamentos, a natureza salarial só será configurada após o empregado exercer a opção de compra das ações. Isso porque, ao ser contemplado com o benefício e antes de cumprido o período de carência, o empregado tem apenas uma expectativa de direito.

Marcel Cordeiro, compartilha do mesmo entendimento e defende que só haverá natureza salarial quando se configurar o direito de exercer a opção de compra das ações, ou seja, quando ele deixar de ser uma mera expectativa de direito. Todavia, acrescenta

\footnotetext{
${ }^{14}$ MARTINS, Sergio Pinto. Direito do Trabalho. 26 ed. São Paulo: Atlas S.A., 2010. p. 246 e 247
} vol.08, $\mathrm{n}^{\circ}$. 01, Rio de Janeiro, 2015. pp. 21-50 
que há várias espécies de Stock Option Plan e que a natureza legal também dependerá das características de cada plano.

Para ele, terá natureza salarial nas seguintes espécies de Plano de Opção de Compra de Ações: Employee Stock Purchase Plan e Restricted Stocks. Nas demais categorias, possuem mera natureza mercantil.

Employee Stock Purchase Plan (ESPP) é a modalidade de Stock Option por meio do qual os empregados contribuem para o plano, através de descontos em folhas, que se acumulam entre a data de concessão do benefício e a data de exercício da opção.

Nesta espécie de Stock Option, o funcionário efetivamente paga pelas ações, mas recebe abatimento, desconto. Na data da aquisição das ações, a empresa utiliza os fundos acumulados de compra de ações da empresa, em nome dos participantes. $\mathrm{O}$ valor do desconto dependerá de cada plano em específico, podendo ter um valor de até 15\% inferior ao do preço do mercado.

Restricted Stocks ou Ações Restritas é a espécie de Stock Option Plan na qual é estabelecida uma restrição para a aquisição ou venda das ações, como, por exemplo, o cumprimento de metas. São comuns em fusões e aquisições, a fim de evitar a venda prematura que possa afetar negativamente a empresa.

Os argumentos utilizados por Marcel Cordeiro para justificar a natureza salarial dessas duas modalidades de Stock Option Plan é a ausência de onerosidade, habitualidade e a contraprestatividade dessa vantagem, posto que, segundo ele, é concedida pelo trabalho e não para o trabalho.

Contudo, a partir da exposição de cada uma das espécies de Plano de Compra de Ações acima mencionados, verifica-se que, em ambos os casos, as ações são obtidas a título oneroso o que faz, portanto, com que tal justificativa não proceda.

Diante das exposições feitas, infere-se que nas duas primeiras fases do Stock Option Plan, ou seja, quando a opção é concedida ao empregado e quando já há a possibilidade de ele exercer a opção, a natureza deste plano será meramente mercantil. Isso significa dizer que as Stock Options não incorporarão à remuneração do obreiro, ou seja, não terão natureza salarial.

A partir da terceira etapa, qual seja, aquela em que o trabalhador exerceu a sua opção, a natureza das Stock Options será determinada pelas peculiaridades de cada plano. 
Nesse sentido, é preciso, antes de mais nada, verificar se a concessão tem caráter contraprestativo. Em outras palavras, deve-se averiguar se o empregado recebeu o benefício como uma forma de retribuição pelos seus serviços desempenhados.

Neste ponto, um fator importante que deve ser observado é a abrangência da extensão do plano. Se o Stock Option Plan for um proveito que poderá abranger qualquer empregado da firma, não há que se falar em caráter retributivo, uma vez que as Stock Options não passam de uma vantagem concedida para aqueles que pertencem à companhia.

Em contrapartida, se for restrito a determinados funcionários, ou seja, concedidas discricionariamente, como, por exemplo, apenas aos grandes executivos, é possível que seja configurada sua natureza salarial, posto que é possível que seja concedido como forma de complementação da remuneração do empregado.

Não basta, porém, que a opção de compra seja concedida como forma de contraprestação, devendo, também, ser oferecida gratuitamente, ou seja, sem que o empregado tenha que dispor de seus recursos financeiros para obtê-las.

Para isso, insta examinar, os métodos de exercícios de cada plano, que são os seguintes: Compra à Vista (Cash Purchase), Swap de Ações, Recarga (Reload), Venda no Mesmo Dia (Same-day-sale), e Venda Descoberta (Sell-to-cover).

Como o próprio nome já diz, na Cash Purchase, as ações devem ser compradas à vista. Os impostos e tarifas associadas à compra deverão ser pagos igualmente à vista pelo empregado beneficiado, ou com parcela das ações que teria o direito de comprar.

O termo "swap" significa troca, permuta. No método Swap de Ações o obreiro, após certo período de carência, poderá cobrir o custo do exercício da opção com suas ações. Neste caso, os impostos e tarifas serão pagos pela retenção de parte das ações e as ações remanescentes são entregues na conta de corretagem do empregado.

O método de Recarga é semelhante ao Swap de Ações e, da mesma forma, o trabalhador irá utilizar parte de suas opções para cobrir todos os custos provenientes do exercício da opção. Contudo, além das ações remanescentes, irá receber uma recarga de ações correspondente ao número daquelas utilizadas para liquidar as despesas da opção. Via de regra, o preço de concessão das ações de recarga é o valor de fechamento do mercado do dia anterior ao do exercício da opção, isto se for, pelo menos, $20 \%$ (vinte por cento) superior ao preço de concessão da opção que o funcionário beneficiado 
estiver exercendo. Imperioso ressaltar que o período de exercício da opção das ações de recarga terá a mesma validade, mas não poderão ser vendidas por um prazo determinado que é usualmente de dois anos após o exercício.

Venda no Mesmo Dia é o método através do qual as ações são compradas e imediatamente vendidas, de forma concomitante. Parte do valor obtido com a venda das ações destinam-se a cobrir os custos da opção, impostos e taxas. Aqui, caberá ao empregado balancear o valor de emissão e o preço das ações no mercado para então optar pelo exercício da opção, evidentemente se as ações estiverem majoradas no mercado. O empregado não ficará com nenhuma parcela de ações e, portanto, não há o risco de o empregado ter qualquer perda, sendo o lucro algo certo, desde que o preço de emissão obviamente seja inferior ao preço do mercado.

A Venda Descoberta é semelhante à Venda no Mesmo Dia. A diferença é que o empregado privilegiado utiliza parte das ações para cobrir o custo total do exercício da opção, e as ações restantes são depositadas em sua conta de corretagem e o valor em dinheiro entregue é entregue a ele.

A partir do exame realizado acima, percebe-se que, em apenas dois métodos de exercício de opção, as Stock Options não terão qualquer encargo para o trabalhador que são as modalidades de Venda no Mesmo Dia e Venda Descoberta. -, além de gerar acréscimos ao patrimônio do mesmo. Isso se deve ao fato de que o empregado nessas duas modalidades não conserva consigo nenhuma ação, mas tão somente o lucro proveniente das mesmas, ou seja, não se submete a riscos. É exatamente por essa razão que poderá ser atribuída a natureza salarial.

Nos demais métodos - Compra à Vista (Cash Purchase), Swap de Ações e Recarga (Reload) - o caráter mercantil é evidente, visto que o empregado figura como um investidor e assume os riscos do negócio.

A habitualidade é outra característica salarial cuja existência deve ser avaliada no Plano de Opção de Compra de Ações. Ao se abordar sobre as fases e características das Stock Options, foram estudadas duas espécies de carência: Carência Direta (Straight Vesting) e Carência em Passos (Step Vesting). Viu-se que, em ambas, a cada ano o empregado poderá exercer uma certa percentagem de opções, que poderá variar ou não.

Ora, indubitável é a presença de habitualidade nessas duas modalidades de carência e, portanto, poderá ser configurado o caráter salarial das Stock Options. 
Do acima exposto, depreende-se que, a depender das características do Stock Option Plan, poderá lhe ser atribuído o caráter mercantil ou salarial. Este último será configurado quando presentes o caráter contraprestativo, gratuito (quanto a não gerar encargos para o trabalhador), habitual e quando enriquecer o patrimônio do empregado.

Nesse sentido, deve-se dizer que, sendo declarada a natureza salarial das Stock Options, será o lucro obtido pelo empregado que será considerado para fins de efeitos nas verbas trabalhistas do mesmo, e não o valor de emissão, valor de mercado ou as Stock Options propriamente ditas.

Por fim, qual classificação deve ser concedida a esse lucro que foi considerado como parcela remuneratória?

A fim de solucionar essa questão, cita-se, mais uma vez, Maurício Godinho Delgado:

Há figuras que não têm originariamente natureza salarial, mas que, em virtude de uma conformação ou utilização fraudulenta no contexto da relação empregatícia, passam a ser tratadas como salário: são parcelas salariais dissimuladas. Registre-se que, caso utilizadas regularmente, tais parcelas não teriam, sem dúvida, natureza salarial. Entretanto, sua utilização irregular, com objetivos contraprestativos disfarçados, frustrando a finalidade para a qual foram imaginadas, conduz ao reconhecimento de seu efetivo papel no caso concreto, qual seja de suplementação, ainda que dissimulada, da contraprestação paga ao empregado pelo empregador. [... $]^{15}$

Portanto, com base na lição do autor, conclui-se que, sendo reconhecida a natureza salarial do lucro obtido por meio do Stock Option Plan, o mais correto é que este seja classificado como parcela salarial dissimulada.

\section{DECISÕES JUDICIAIS SOBRE STOCK OPTIONS}

Após a análise do entendimento doutrinário acerca da natureza legal das Stock Options, parte-se para o exame de algumas decisões e suas respectivas justificativas, a fim de se verificar o posicionamento dos juízes e turmas que compõem os órgãos da Justiça do Trabalho.

\footnotetext{
${ }^{15}$ DELGADO, Maurício Godinho. Curso de Direito do Trabalho. 4 ed. São Paulo: LTr, 2005. p. 695.
} vol.08, n. 01, Rio de Janeiro, 2015. pp. 21-50 43 


\section{Tribunal Superior do Trabalho}

O Tribunal Superior do Trabalho (TST), órgão de cúpula da Justiça do Trabalho, muito embora não tenha editado até julho de 2013 Súmula a respeito do tema em questão, tem pacificado o entendimento de que às Stock Options não deve ser conferida a natureza de contraprestação, isto é, natureza salarial, mas sim de indenização.

Como exemplo, parte-se para a análise do Agravo de Instrumento em Recurso de Revista de no. TST-AIRR-85740-33.2009-5.03.0023. Através da demanda, o Agravante pleiteava o reconhecimento da natureza salarial do Plano de Stock Option e de Restricted Stock Units.

Já restou elucidado que Restricted Stock Units ou Ações Restritas é uma espécie de Plano de Concessão de Ações, através do qual é estabelecida uma condição, restrição, para a subscrição ou venda das ações.

Em acórdão da lavra do eminente Ministro Maurício Godinho Delgado - Recuso de Revista no. 217800-35.2007.5.02.0033 - foi negado seguimento ao Agravo, nos seguintes termos:

4. STOCK OPTIONS. O programa pelo qual o empregador oferta aos empregados o direito de compra de ações (previsto na Lei de Sociedades Anônimas, n. $6404 / 76$, art. $\left.168, \S 3^{\circ}\right)$ não proporciona ao trabalhador uma vantagem de natureza jurídica salarial. Isso porque, embora a possibilidade de efetuar o negócio (compra e venda de ações) decorra do contrato de trabalho, o obreiro pode ou não auferir lucro, sujeitando-se às variações do mercado acionário, detendo o benefício natureza jurídica mercantil. O direito, portanto, não se vincula à força de trabalho, não detendo caráter contraprestativo, não se lhe podendo atribuir índole salarial. Recurso de revista não conhecido.". ${ }^{16}$

Neste caso, o Ilustre Ministro pautou-se em uma das características inerentes do Stock Option Plan, qual seja, a volatilidade. Para ele, ainda que a concessão da benesse seja decorrente do contrato de trabalho, o fato de o empregado sujeitar-se às oscilações

\footnotetext{
${ }^{16}$ TST. Disponível em: <https://aplicacao5.tst.jus.br/consultaProcessual/consultaTstNumUnica.do?co nsulta $=$ Consultar\&conscsjt $=$ \&numeroTst $=2178$ oo \&digitoTst $=35 \&$ anoTst $=2007 \&$ orgaoTst $=5 \&$ tribunalT st $=02 \&$ varaTst $=0033 \geq$. Acesso em: 16/07/2013. 
do mercado acionário, sendo o lucro algo incerto, afasta a natureza contraprestativa do plano.

Nesse exato sentido, foi o acórdão do Agravo de Instrumento de ㄲo. TSTAIRR85740-33.2009.5.03.0023, proferido pelo mesmo respeitável Ministro, nos seguintes termos:

AGRAVO DE INSTRUMENTO. RECURSO DE REVISTA. Compra de ações vinculada ao contrato de trabalho. Stock options. Natureza não salarial. Exame de matéria fática para compreensão das regras de aquisição. Limites da Súmula № 126/TST. As stock options, regra geral, são parcelas econômicas vinculadas ao risco empresarial e aos lucros e resultados do empreendimento. Nesta medida, melhor se enquadram na categoria não remuneratória da participação em lucros e resultados (art. $7^{\circ}$, XI, da CF) do que no conceito, ainda que amplo, de salário ou remuneração. De par com isso, a circunstância de serem fortemente suportadas pelo próprio empregado, ainda que com preço diferenciado fornecido pela empresa, mais ainda afasta a novel figura da natureza salarial prevista na CLT e na Constituição. De todo modo, torna-se inviável o reconhecimento de natureza salarial decorrente da possibilidade de compra de ações a preço reduzido pelos empregados para posterior revenda, ou a própria validade e extensão do direito de compra, se a admissibilidade do recurso de revista pressupõe o exame de prova documental - O que encontra óbice na Súmula no 126/TST. Agravo de instrumento desprovido. ${ }^{17}$

\section{Tribunais Regionais do Trabalho}

Pode-se dizer que a questão acerca da natureza jurídica das Stock Options, ainda que não regulamentada especificamente na esfera trabalhista e previdenciária, e que seja extremamente controvertida, já é praticamente pacificada na doutrina pátria e no Tribunal Superior do Trabalho, no sentido do caráter mercantil. Todavia, o mesmo já não pode se dizer dos Tribunais Regionais do Trabalho, persistindo a contenda.

Na Reclamação Trabalhista sob o oo. o052900-54-2000-5-01-0018 afirmou o Reclamante ter o direito de negociar no mercado bursátil 9.818 ações da empresa "Cisco

\footnotetext{
${ }^{17}$ TST. Disponível em: <https://aplicacao5.tst.jus.br/consultaProcessual/consultaTstNumUnica.do?co nsulta $=$ Consultar\&conscsjt $=\&$ numeroTst $=85740 \&$ digitoTst $=33 \& \mathrm{anoTst}=2009 \&$ orgaoTst $=5 \&$ tribunalTs $\mathrm{t}=03 \&$ varaTst $=0023 \geq$. Acesso em: 16/07/2013. 
Systems, Inc.", que lhe foram entregues como parte integrante de sua remuneração. Por essa razão, pleiteia que os valores das ações devem ser integrados como parcela remuneratória.

Este pedido, entretanto, foi julgado improcedente pelo juiz de piso, motivo pelo qual o Reclamante interpôs recurso ordinário adesivo. Contudo, o juízo ad quem manteve a decisão de primeira instância.

A $7^{\underline{a}}$ Turma do Tribunal Regional do Trabalho da $1^{\underline{a}}$ Região manifestou entendimento no sentido de que as Stock Options não constituem uma forma de remuneração pelos serviços prestados pelo empregado, ou seja, não possuem natureza salarial. O contrato decorrente do Plano de Opção de Ação é meramente mercantil, oneroso, sujeito às flutuações do mercado e, consequentemente, aos riscos da atividade. O empregado, ao receber o benefício da opção de compra de ações, assume totalmente o risco de ganhar ou perder com a venda das ações.

Segundo este juízo o objetivo do Plano de Stock Option é manter o quadro dos bons empregados e incentivar suas produções e, de forma alguma, servir como uma forma de contraprestação salarial.

No caso em tela, não restou devidamente demonstrado o exercício da opção das 9.818 (nove mil, oitocentas e dezoito) ações, e tampouco foi comprovado o preenchimento dos requisitos estabelecidos para que a de opção de compra de ações deixasse de ser apenas uma expectativa de direito. Por esse motivo a Turma negou provimento ao pagamento dessas ações.

Ademais, por entender que as Stock Options não consistem em instituto que objetiva remunerar o trabalhador, não tendo, portanto, natureza salarial, e sim mercantil, foi igualmente negado provimento ao pleito autoral de integração ao salário do valor das ações.

Já na Reclamação Trabalhista noo. oo98200-05-2003-5-01-0o6o, a 6a Turma do mesmo Tribunal entendeu da seguinte maneira: 
O oferecimento de ações da empresa ao empregado sem qualquer custo caracteriza a natureza salarial do benefício "Stock Option", a justificar a incidência da contribuição previdenciária sobre a referida parcela. ${ }^{18}$

Do que se percebe é que a natureza legal das Stock Options é um tema tão controvertido, que o posicionamento pode variar entre as Turmas de um mesmo Tribunal. Contudo, cada entendimento também irá depender das características de cada Plano de Opção de Compra de Ações em cada caso concreto.

\section{CONCLUSÃO}

O presente artigo teve como centro de gravidade as discussões travadas na doutrina e jurisprudência acerca da natureza legal atribuída ao lucro proveniente com o exercício da opção de compra e posterior venda das ações, uma vez que não há qualquer tipo de regulamentação legal no campo trabalhista, previdenciário e tributário.

Sabe-se que os pagamentos realizados pelo empregador ao empregado podem ser em pecúnia ou em bens, mas só integrarão a sua remuneração desde que pagos pelos trabalhos realizados, ou seja, como forma de retribuição do trabalhador; que seja feito de forma habitual; e que não gere qualquer onerosidade ao obreiro, uma vez que os riscos do negócio devem ser assumidos integralmente pelo empregador.

Percebe-se ainda que, embora se trate de tema polêmico, a maior parte da doutrina brasileira, já se posicionou no sentido de que os lucros advindos do Stock Option Plan não devem ser incorporados à remuneração do empregado. Dentre os principais argumentos estão: (i) o risco assumido com o negócio, dado às oscilações do mercado acionário, e que pode culminar tanto em lucros, como gerar prejuízos ao trabalhador; (ii) a onerosidade da benesse; (iii) a falta de habitualidade da concessão; (iv) a ausência do caráter contraprestativo, uma vez que o objetivo principal é incentivar e reter a mão de obra de empregados chaves.

No mesmo sentido, está a maior parte do entendimento jurisprudencial, principalmente do Tribunal Superior do Trabalho.

\footnotetext{
${ }^{18}$ TRT $1^{\mathrm{a}} \quad$ Região. Disponível em: <http://www.trt1.jus.br/consulta-processualview?_consultaprocessualviewportlet_WAR_trtconsultaprocessualportlet_indicadorNumeroProcesso $=$ CNJ\&_consultaprocessualviewportlet_WAR_trtconsultaprocessualportlet_sqProcesso $=7916450 \&$ \&o nsultaprocessualviewportlet_WAR_trtconsultaprocessualportlet_numeroProcessoConsultado=00982 oo-05.2003.5.01.006o $\geq$. Acesso em: 16/o7/2013.
} 
Na posição diametralmente oposta, estão aqueles que defendem a natureza salarial das Stock Options, ainda que em minoria. Contudo, percebeu-se que, para que os lucros advindos do exercício da opção possam ser considerados como parcela remuneratória, é necessário analisar, em cada caso concreto, as características do Plano de Concessão.

Neste particular, as modalidades de exercício Venda no Mesmo Dia e Venda Descoberta permitem que haja o reconhecimento da natureza salarial, uma vez que em ambas ao trabalhador não recai qualquer risco.

Da mesma forma pode ocorrer nos planos que adotem o método de Carência Direta e Carência a Passos, já que resta evidente a habitualidade, uma vez que o empregado poderá exercer uma certa percentagem de opções por ano, podendo ser fixa ou variada.

Assim, declarada a natureza salarial da percepção monetária auferida pelo Plano de Concessão de Ações, estas parcelas deverão fazer parte da base de cálculo das verbas trabalhistas para todos os fins e, ainda, poderá o plano ser incorporado ao contrato de trabalho, na hipótese em que se verificar que a mão de obra foi atraída por essa vantagem.

Por fim, insta mencionar que, caso seja declarada a natureza salarial das Stock Options, estas deverão ser conhecidas como parcelas salariais dissimuladas, uma vez que fogem do seu objetivo original, que é o de alinhar os interesses dos empregados com o do empregador, estimulando seus trabalhadores, sendo concedidas como uma forma de contraprestação pelos serviços realizados.

THE LEGAL NATURE OF STOCK OPTIONS IN THE BRAZILIAN LABOR LAW

\section{Abstract}

The present article aims to analyze the Stock Option Plan, that is the system, which seeks to stimulate employee, and, consequently, to increase the productivity of the employer, a joint-stock company, through granting of stock option, usually in a more benefic condition compared to that found in the stock market. Because of the absence of specific law, on labor and social security scopes there is a discussion debated among 
labor jurists and the judicial entities belonging to the Labor Justice structure over the legal nature which should be imputed to Stock Options and, consequently, the effects produced on the employment relationship. Exercised the stock option, the beneficiary employee can, after the vesting, sell his stocks on the propitious time, when the stocks are at high value. From the eventual profit obtained by employee with the sell of his stocks comes the problem about the legal nature of the Stock Option, in other words, should it receive a salary treatment or only a commercial agreement treatment?

Keywords: Stock option. Salary. Stockmarket.

\section{REFERÊNCIAS}

BARROS, Alice Monteiro de. Curso de Direito do Trabalho. 2 ed. São Paulo: LTr, 2006.

CARF. Acompanhamento Processual. Disponível em: <http://carf.fazenda.gov.br/sin con/public/pages/index.jsf $\geq$. Acesso em 07/07/2013.

CARVALHOSA, Modesto. Comentários à Lei de Sociedades Anônimas. $3^{0}$ volume. 5 ed. São Paulo: Saraiva, 2011.

CASSAR, Vólia Bomfim. Direito do Trabalho. 4 ed. Rio de Janeiro: Impetus, 2010.

Direito do Trabalho. 6 ed. Rio de Janeiro: Impetus, 2012.

CNF. CARF aprecia os primeiros processos sobre Stock Options. Disponível em: $<$ http://www.cnf.org.br/noticia/-/blogs/carf-aprecia-os-primeiros-processos-sobrestock-options $\geq$. Acesso em: 10/07/2013.

COELHO, Fábio Ulhoa. Curso de Direito Comercial: Direito de Empresa. 16 ed. $<$ São Paulo: Saraiva, 2012.

CORDEIRO, Marcel. A Natureza Salarial dos Valores Distribuídos por Meio dos Planos de Opção de Ações. Monografia - Curso de Especialização em Direito do Trabalho, Pontifícia Universidade Católica de São Paulo, 2003.

DAL MAS, Viviane Castro Neves Pascoal. Stock Options na Relação de Emprego. São Paulo: LTr, 2008.

DELGADO, Maurício Godinho. Curso de Direito do Trabalho. 4 ed. São Paulo: LTr, 2005 .

Curso de Direito do Trabalho. 11 ed. São Paulo: LTr, 2012.

HOODDY, Jason. Recent History of Employee Stock Options. Disponível em: <http://www.financialpolicy.org/dscprimerstockoptionza.htm>. Acesso em: 13/o6/2013. 
IGNÁCIO, Laura; RESENDE, Thiago. Carf decide que plano de stock option deve ser tributado. Disponível em: <http://www.valor.com.br/legislacao/3169424/carf-decideque-plano-de-stock-option-deve-ser-tributado\#ixzz2Ybs8Ogy6>. Acesso em: 10.07.2013.

INVESTOPEDIA. Employee Stock Purchase Plan - ESPP. Disponível em: $<$ http://www.investopedia.com/terms/e/espp.asp $\geq$. Acesso em: o6/o7/2013.

MARTINS, Sergio Pinto. Direito do Trabalho. 26 ed. São Paulo: Atlas S.A., 2010.

OLIVEIRA, Ana Paula Braga de. Stock Options no Direito do Trabalho Brasileiro. Monografia - Curso de Pós Graduação Lato Sensu em Direito e Processo do Trabalho, Universidade Cândido Mendes - AVM Faculdade Integrada, 2013.

RUIZ, Acíar Alzaga. Las Stock Options - Un estúdio del punto de vista del derecho del trabajo y de la seguridad social. Madrid: Civitas Ediciones, 2003.

SUSSEKIND, Arnaldo. Curso de Direito do Trabalho. Rio de Janeiro: Renovar, 2002.

STF. Disponível em <http://www.stf.jus.br/portal/principal/principal.asp > Jurisprudência. Acesso em 05/07/2013.

TST. Disponível em:<http://www.tst.jus.br $\geq$. Jurisprudência. Acesso em 07/o7/2013.

Disponível em: <http://www.tst.jus.br $\geq$. Jurisprudência/ Consulta Unificada. Acesso em 16/03/2013.

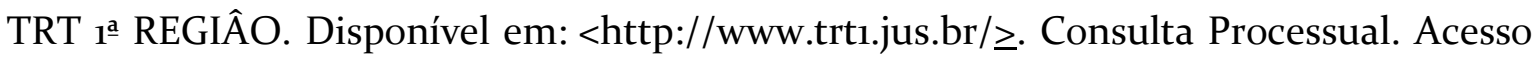
em 16/03/2013.

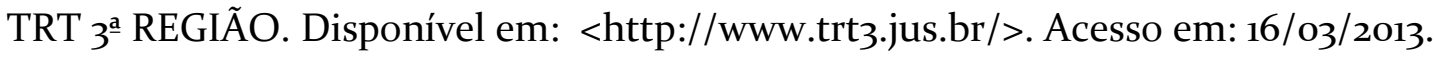

Trabalho enviando em 07 de novembro de 2014.

Aceito em 22 de janeiro de 2015. 